\title{
Wellness Motivation in Cardiac Rehabilitation: The Role of Self-Knowledge in Cardiovascular Risk Modification
}

\author{
Julie Fleury, ${ }^{1 \dagger}$ Constantine Sedikides ${ }^{2 \ddagger}$ \\ ${ }^{1}$ Division of Community Health, College of Nursing, Arizona State University, Tempe, AZ \\ ${ }^{2}$ School of Psychology, University of Southampton, Southampton, England \\ Accepted 13 January 2007
}

\begin{abstract}
Understanding the factors that motivate behavioral change is central to health promotion efforts. We used qualitative descriptive methods in an effort to understand the role of self-knowledge in the process of risk factor modification. The sample consisted of 17 men and 7 women with diagnosed coronary heart disease, who were attempting to initiate and sustain programs of cardiovascular risk modification. Participants described selfknowledge in terms of three contextually situated patterns: representational, evaluative, and behavioral action. Results reinforce the motivational role of the self and highlight the importance of understanding dimensions of selfknowledge relevant to cardiovascular risk reduction. () 2007 Wiley Periodicals, Inc. Res Nurs Health 30:373-384, 2007
\end{abstract}

Keywords: self-knowledge; wellness motivation; cardiac rehabilitation

Coronary heart disease remains the largest single cause of death in the United States (American Heart Association [AHA], 2001). Although physical and behavioral characteristics that increase coronary heart disease (CHD) risk have been established, the challenge of promoting sustained lifestyle change to reduce or eliminate risk behaviors has not been fully met. Despite the benefits of primary and secondary prevention in the reduction of cardiovascular risk, lack of adherence is a fundamental problem in risk modification efforts (Miller, Hill, Kottke, \& Ockene, 1997; Smith et al., 2001).

Although motivation has been identified as a primary determinant of health behavior change, interventions designed to enhance motivation in behavioral change have shown limited effectiveness (Krummel et al., 2001; Miller et al., 1997). Thus, there is a need to better understand how motivation contributes to the initiation and maintenance of behavioral change. Wellness motivation, in particular, has been described as a

The authors thank cardiac rehabilitation center participants, administrators, and staff for their contributions.

Contract grant sponsor: NIH/NINR; Contract grant number: NR06258.

Contract grant sponsor: Sigma Theta Tau International.

Correspondence to Julie Fleury, Arizona State University, 500 North 3rd St., Phoenix, AZ 85004.

†Hanner Professor.

$\ddagger$ Professor.

Published online in Wiley InterScience (www.interscience.wiley.com)

DOI: 10.1002/nur.20225 
behavioral change process that includes recognizing the need for change, initiating behaviors consistent with valued goals, and maintaining those behaviors over time (Fleury, 1991, 1996). This process also entails generating valued goals, imagining opportunities for action, as well as carrying out goals intended to bring about health-relevant behavioral change. Within this context, a promising area of research involves conceptions of the self, and how the ways in which individuals define, describe, interpret, and act on valued goals guide risk-reducing behaviors (Whaley, 2003).

The self-system is increasingly being recognized as a critical antecedent or correlate of motivation in behavioral change (Anderman, Anderman, \& Griesingner, 1999; Bonanno, Rennicke, \& Dekel, 2005; Mischel \& Morf, 2003). Researchers have explored aspects of self-knowledge, defined as the subset of an individual's stored knowledge about her or his personality (Baumeister, 1998), including ideal or feared selves (Oyserman, Bybee, Terry, \& HartJohnson, 2004; Oyserman \& Fryberg, 2006), goals and plans for action (Gollwitzer, Fujita, \& Oettingen, 2004; Oettingen \& Gollwitzer, 2001), changes in goals and plans across the life span (Heidrich \& Ryff, 1993; Roberts, O’Donnell, \& Robins, 2004), and personal efficacy in behavioral domains (Cervone, Mor, Orom, Shadel, \& Scott, 2004; Maddux \& Gosselin, 2003). The goals, motivations, and actions involved in behavioral change are linked to the self-system, as the self is the central point of reference for cognition, emotion, motivation, and social behavior (Sedikides, 2003; Sedikides, Gaertner, \& Toguchi, 2003; Sedikides \& Gregg, 2003).

Self-knowledge reflects those aspects of a dynamic self-concept that develop through internal self-evaluation and interpersonal experiences, and reflect motivational needs expressed as individual goals (Markus \& Nurius, 1986; Sedikides \& Gregg, 2006; Sheldon, 2004). Moreover, self-knowledge influences the interpretation of new information about the self (Sedikides \& Green, 2000, 2004), as well as behavior toward the self (Bagozzi, Moore, \& Leone, 2004; Baumeister \& Vohs, 2004). Selfknowledge provides the conceptual foundation for assigning meaning to events, establishing goals and standards for behavior, gauging one's selfefficacy, and developing strategies for the regulation of behavioral outcomes (Kendzierski, 1997; Pridham, 1993; Stein, 1995; Taylor, Pham, Rivkin, \& Armor, 1998). Thus, self-knowledge likely plays a primary role in regulating individual motivation and decision-making activities relevant to the formation of goals and health behaviors central to cardiovascular risk reduction. In the sense that motivation implies potential change from present to future, self-knowledge operationalizes and represents motivation in the self-concept (Dunkel \& Kerpelman, 2006; Markus \& Nurius, 1986; Unemori, Omoregie, \& Markus, 2004).

The development of theory and practice that focus on individual efforts in initiating and maintaining positive health behaviors must surely include an investigation of how individual motives are transformed into personal intentions and plans. Inquiry into the representation of self-knowledge promises to provide an increased understanding of the processes through which changes in individual health status occur and the patterning of individual behavior in interaction with the social environment. Few researchers have explored the role of self-knowledge in cardiovascular risk modification from the perspective of older adults with diagnosed CHD. Thus, the purpose of this research was to rely on self-knowledge as a basis for understanding how individual motives, expectations, and goals are manifested within the process of risk factor modification among those with CHD. This research builds upon previous work on the role of the self in health behavior to further clarify the content and function of self-knowledge in motivating behavioral change, and to establish a relevant theoretical basis for the assessment of personally relevant behavioral domains, individual determination of potential, and the prediction of future behavior (Black, Stein, \& Loveland-Cherry, 2001; Fleury, Sedikides, \& Donovan, 2002; Quellette, Hessling, Gibbons, Reis-Bergan, \& Gerrard, 2005).

\section{METHODS}

We present a secondary analysis of inductively generated data, using a qualitative descriptive design (Sandelowski, 2000). The parent study used grounded theory methodology to identify, describe, and provide an analysis of the psychological and social processes involved in the initiation and maintenance of cardiovascular health behavior over time (Fleury, 1991). Empowering potential, the basic social process identified from the data, explained individual motivation in health behavior change. In this secondary analysis, we sought a more complete description and conceptualization of the role of selfknowledge in motivation for health behavior change and the modification of cardiovascular risk. 


\section{Sample}

The sample consisted of 24 individuals with CHD who were in the process of initiating and sustaining programs of health behavior change. To be included, participants had to (a) be engaged in a formal and monitored cardiac rehabilitation program; (b) have clinically diagnosed CHD; (c) be able to speak English; and (d) give informed consent. Participants were recruited from a cardiac rehabilitation center that served patients of diverse socioeconomic backgrounds from both urban and outlying rural communities. The program offered a variety of services, such as smoking-cessation, nutritional counseling, stress management, aerobic exercise, pharmacy or medication classes, and weight training.

Of the 24 participants, 17 were men and 7 were women. The participants' ages ranged from 38 to 79 , with a mean age of 58 ( \pm 8.2 years). Eight participants were referred to cardiac rehabilitation after acute myocardial infarction. Six had undergone coronary artery bypass graft surgery after myocardial infarction, whereas three had undergone this surgery after a clinical diagnosis of myocardial ischemia. At the time of the study, participants had been involved in cardiac rehabilitation for an average length of 10 weeks. The majority $(n=19)$ were married. Seven were employed full time, 6 were employed parttime, and 11 had retired. All participants were high school graduates, and 10 had some college education.

\section{Procedures}

Data collection involved the use of increasingly structured interviews over time with individuals attempting to implement health behavior change. Participant recruitment and data collection took place over 7 months in 1989-1990. Attendance at seminars on risk factor modification and at exercise sessions allowed the investigators to become familiar with individuals at different stages in the lifestyle change process. The recruitment protocol included determination of initial eligibility and was guided by maximum variation and theoretical sampling methods (Curtis, Gesler, Smith, \& Washburn, 2000; Patton, 2002; Sandelowski, 1995). Through theoretical sampling, data sources were selected to test, elaborate, and refine identified categories. For example, participants were sampled based on their length of time in cardiac rehabilitation, and, thereby, experience in the process of risk modification. Maximum variation sampling was used to explore the common and unique manifestations of self-knowledge across a range of participant experience with health behavior change. Six participants described themselves as struggling with recommended health behavior change, which allowed us both to explore variations in the data related to levels of motivation and to better define self-knowledge across differing levels of motivation for health behavior change.

Potential participants were recruited by a research team member. During this initial meeting, participants were informed of the study purpose and protocol and assured of confidentiality. Those who met eligibility criteria and who agreed to participate reviewed and signed the study consent form. Following the initial recruitment and informed consent process, participants were contacted to arrange a time and place for the interview.

\section{Data Collection}

Data collection began with unstructured interviews. Interviews were conducted in a private area, such as an empty classroom, chosen by each participants. Interview data were audiotaped in their entirety. The primary questions designed to explore self-knowledge within the process of health behavior change were: (a) "How do you see yourself, both now and in the future?", (b) "How do the ways that you see yourself help you to determine goals for health behavior change?", and (c) "How do the ways that you see yourself help you to determine strategies for health behavior change?" The questions for each interview followed the same general format. Interviews were conducted with participants until either the informational value of participants' answers was exhausted or informational redundancy was reached. Of the 24 participants, 4 were interviewed twice. These four were the individuals who we thought could best clarify and verify emerging conceptualizations.

\section{Data Analysis}

Data were analyzed using qualitative content analysis, consistent with a conventional approach. Conventional qualitative content analysis was used for the subjective interpretation of the content of narrative data and for the descriptions of a phenomenon through the process of coding and identifying themes or patterns (Hsieh \& Shannon, 
2005). Analysis was focused on providing a summary of the informational contents of the data, identification of data codes, and the construction of categories. Data analysis was conducted at two levels. In the first level, researchers reviewed the statements from the interviews in an effort to understand the data in context. In the second level, data were coded using a lineby-line analysis of the transcribed interviews and the coding of data into relevant sentences and phrases. Codes specific to self-knowledge were compared both within and across interviews, with related codes clustered to determine categories of self-knowledge and their properties. Data were then classified to formulate distinct categories and synthesize themes of meaning.

\section{Trustworthiness of the Data}

The techniques used to optimize the trustworthiness of data generated were based on criteria established for naturalistic inquiry (Guba \& Lincoln, 2005; Lincoln \& Guba, 1985). Credibility refers to having confidence in the truth of the findings as experienced by the participants. Regular interaction with participants during data collection and analysis provided validation and clarification of the data. Knowledgeable peers, including cardiac rehabilitation staff, validated the rationale for data categorization. Referential adequacy was optimized by comparing the developing conceptualization with related data sources on the role of the self in health behavior and health-related motivation. Through a literature review, conceptualizations and empirical data relevant to categories were identified and used to ground coding and categorization decisions. Dependability refers to the ability to track variance in the data over time. The use of process and analytic memos throughout the course of the inquiry optimized dependability. After each interview, the investigators included in memos their decisions about the data and the sampling procedures in order to clarify data patterns. These decisions were reviewed and discussed with the research team. Confirmability refers to the interpretational objectivity of the data. Confirmability was maintained by exploring alternative explanations with both cardiac rehabilitation staff and participants. The initial categorizations were discussed with cardiac rehabilitation staff. Furthermore, member checks of data categorizations were conducted with participants, as a forum for discussion and clarification of investigator conceptualizations.

\section{RESULTS}

Interview data provided relevant information about the role of self-knowledge in guiding efforts to modify cardiovascular risk. The content of selfknowledge consisted of the delineation of valued goals, health outcomes, and outcome-consistent action statements. Self-knowledge contained individualized conceptions of both desirable and undesirable future health outcomes, as well as detailed constructions of behavioral plans to realize or avoid these outcomes. Participants described health-related self-knowledge in terms of three socially and contextually situated patterns: self-knowledge as a representational process, self-knowledge as an evaluative process, and self-knowledge as a behavioral action process. These patterns of self-knowledge were interactive rather than mutually exclusive and illustrate the complexity of self-knowledge in motivating the initiation and maintenance of health behavior change (Fig. 1).

\section{Self-Knowledge as a Representational Process}

Self-knowledge provided a context of meaning through which participants interpreted past and current behavior and constructed self-relevant representations of what might be possible for them in the future (Dunkel \& Kerpelman, 2006; Markus \& Nurius, 1986). Participants discussed their hopes and fears for future health outcomes and elaborated valued goals that guided the initiation and maintenance of behavioral change. The representational process refers to responses to the question: "What will I become in light of what has happened to me?" As an immediate response to the diagnosis of CHD, participants wondered about what might be possible for their recovery and began to envision these possibles as goals to guide behavior. The possibles served as personalized representations of relevant motives and threats (Dunkel \& Kerpelman). Self-knowledge as a representational process formed a context for goal development related to risk modification within three categories: the desired self, the socially created self, and the feared self.

The desired self reflected the construction and awareness of personally relevant behavioral domains that provided a direction for change and growth (Yowell, 2002). The recognition of desired possible selves fostered the construction of personal goals for the realization of valued health outcomes. The desired self was manifested 


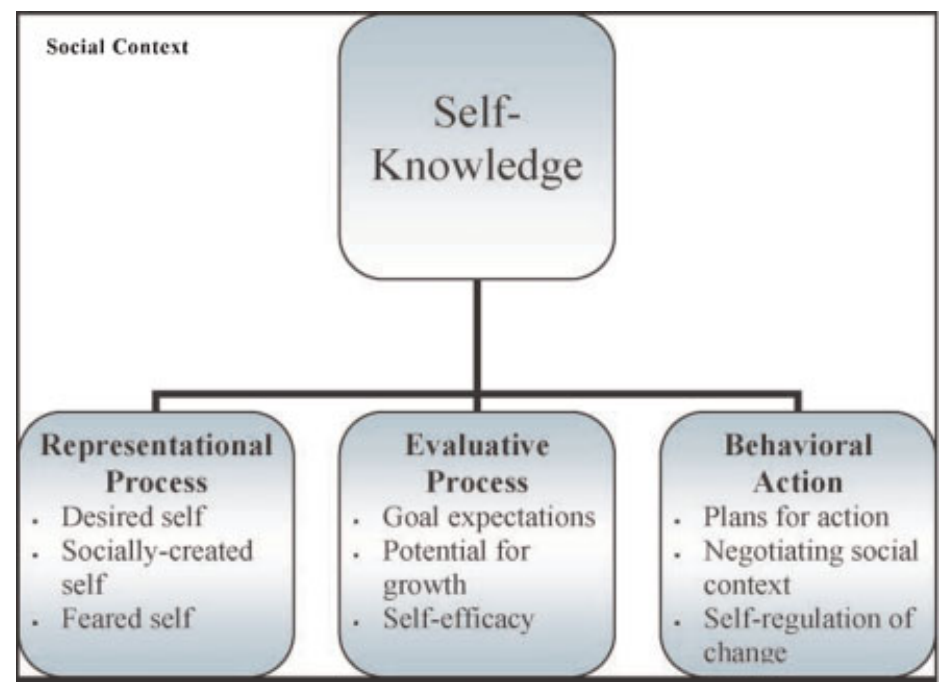

FIGURE 1. Patterns of self-knowledge.

in representations of positive health outcomes that included general outcomes such as personal independence, as well as specific outcomes such as a weight loss of 25 pounds. In reflecting on desired goals and health outcomes during the process of rehabilitation, one participant noted:

I think that you always have the images of how you want to be. They're with you throughout the changes. It's a part of setting new goals, creating new things for yourself. The images are directives throughout the changes.

The socially created self refers to responsiveness to social experiences and societal norms for healthy behavior and health outcomes (Shepard, 2003). Socially created self-knowledge directed goal formation consistent with the values and expectations of family, friends, and society at large. Participants often interpreted their behavior in terms of how others would respond or be affected. Thus, socially created self-knowledge facilitated an examination of the role of riskproducing behaviors in relation both to personal values for acceptance and societal values. Two participants discussed the role of the socially created self as motivating attempts to quit smoking. As one man observed:

I was laying in bed one night, and I was thinking about how could I justify to my family if I was laying in the hospital dying of something caused by cigarettes. I imagined myself laying there and I thought: "it's wrong for me to do that." I thought: "I owe it to my family not to do that." That's the way I convinced myself.

\section{Another woman noted:}

You think about your own future and that of your family... .you examine your options.

The feared self reflected an awareness of the negative future consequences of risk-producing behaviors (Yowell, 2000). Representations of personal fears included debilitation following a cardiac event or sequelae from a cerebrovascular accident. Such fears also served to motivate risk factor modification in that they directed behavior to avoid feared outcomes. In discussing her decision to participate in an outpatient cardiac rehabilitation program, an older woman shared aspects of her feared self:

I think a lot about the future. Even though I'm old, I don't feel like I'm old. I want to continue to be able to do things for myself. I don't want to end up in a nursing home. You know, you can't help but think of that. You think of what could happen.

\section{Self-Knowledge as an Evaluative Process}

Within the evaluative process of self-knowledge, participants moved from generalized conceptions of personal goals or possibles to the organization and specification of directive goals and selfrelevant expectations and beliefs by which to judge their efforts. Self-knowledge provided the basis for an appreciation of the meaning of both current and past behavior in terms of individual 
standards for goal achievement, potential for growth and change, and self-efficacy. Through self-knowledge, participants established expectations for health behavior change, including outcome expectations, and created a personally relevant evaluative framework for behavior consistent with these expectations (Baumeister \& Vohs, 2004). Self-knowledge formed the evaluative process for efforts to modify risk within three categories: goal expectations, the potential for growth, and self-efficacy.

Goal expectations included the creation of specific short- and long-term goals, as well as expectations for behavioral outcomes. Goal expectations served as a guide in the initiation and regulation of behavioral change over time (Oyserman et al., 2004). Expectations included both personally and socially valued aspects of health behavior such as feeling better, achieving a reduction in cardiovascular risk, and being able to participate more fully in family life. Yet, participants also weighed the pros and cons of behavior in light of their own values. Thus, personal expectations were often the subject of conflict and difficulty for participants in the process of choosing between valued goals and behaviors. Many participants struggled with personal goals for health behavior change in light of equally valued risk behaviors. For some participants, prescribed plans for physical activity, dietary modification, or smoking cessation were inconsistent with personal values or a personally defined sense of self and were, therefore, difficult to follow. One woman described this struggle related to weight loss:

Maybe you had been at an ideal weight at one time. Or maybe at one time in your life, think back to when you really felt good about yourself. Maybe that involved being at a lower weight or maybe that involved being able to perform certain physical activities, so you become encouraged to have that feeling again.

Another woman described her efforts to quit smoking:

I did visualize myself as healthier, with stronger lungs and able to do more. But you also think about life without a very powerful crutch, something that has been with you through some very rough times, a comfort of sorts. It's hard to think about getting through the rest of your life without a cigarette in reach.

As participants' knowledge, self-perception, goals, and experience grew and changed, evaluative criteria for behavior and health outcomes followed suit (Dunkel, 2000). Participants noted that their self-understanding was continually modified and emerging, as they achieved goals and refined behavioral strategies. Indeed, selfknowledge reflected a growth-oriented dynamic component in motivation toward sustained lifestyle change. As one woman reflected on this process:

It seems like, as you go on, your images of where you want to be and what you need to do get more specific. It's an ongoing thing. You always have these pictures in your mind of how you want to be and what it will take to get you there.

Participants gauged their personal efficacy in reference to achievement of valued health outcomes (Oyserman et al., 2002). Participants based their evaluation of personal efficacy both on past experience and the meaning of health behavior change within a specific situation. Self-knowledge that reflected feelings of personal health, independence, and productivity was closely tied to perceptions of efficacy and a sense of possibility in the achievement of valued health outcomes. The recognition of individual attempts to change, as well as acknowledgement of progress in efforts to modify risk, enhanced participants' sense of achievement and efficacy to sustain life changes. In discussing evaluations of personal efficacy to initiate a physical activity program following a cardiac event, one man noted:

As far as my physical condition, I'm optimistic. I can see myself in top condition I know I can get back in top shape. I thought ahead and felt that if I made the changes, and kept up with them that I could get better. I was hopeful of that.

For those participants who perceived themselves as lacking in efficacy, evaluative self-knowledge was less positive. Participants spoke of a sense of hopelessness related to future health outcomes and an inability to create personal resources for risk modification. Although change may have been consistent with desired, socially determined, or feared self-knowledge, participants felt unable to view themselves and their abilities in ways that facilitated positive change. The role of efficacy in motivating behavioral change was evident in the experience of one woman who was attempting to initiate a reduced calorie diet:

I've tried to get back on the diet and it just won't click. I've hit a brick wall and I've never been able to get over that. I just don't see how I can make the changes. I think of the future, and it just seems hopeless. 


\section{Self-Knowledge as a Behavioral Action Process}

Beyond the construction of personalized goals for behavioral change, self-knowledge facilitated the activation of specific processes for achieving desired health outcomes. The behavioral action process comprised the development of behavioral strategies used to transform goals into desired outcomes and, thus, provided a map for guiding behavior, evaluation, and self-regulation. Participants generated plans for action, strategies for negotiating the social context, and mechanisms for self-regulation of behavioral change (Leondari, Syngollitou, \& Kiosseoglou, 1998; Oyserman, Gant, \& Ager, 1995).

In planning behavioral change, participants visualized specific situations and created relevant behavioral strategies to achieve desired outcomes. Strategies served as action guides for behavior, particularly in those situations when difficulties or barriers were encountered. Through an assessment of valued goals and judgments about the means best suited to attain those goals, participants generated plans for goal attainment. As one participant put it:

Even though I know I have to make changes, it still involves a process of decision making. To other people, you aren't doing anything — but really in your mind you are deciding what you should do, before you go ahead and do it.

In negotiating the social context, participants explored the relevance of differing options and compared alternative strategies for behavioral change. These strategies involved negotiating and adjusting to emerging social contexts and reflected a problem-solving approach to risk modification. Through self-knowledge, participants examined the relevance of differing options for behavioral change as a basis for creating realistic plans for change. Participants considered and visualized specific situations and evaluated acceptable alternative outcomes. As one participant noted:

In order to change, you've got to think, "What are the changes that I need to make and how are they going to work?" I get it in my mind what I want to do first and then think about how it will fit into my life. You have to explore your options, what your life is going to look like. Whatever large or small change it is, you've got to visualize that. Then you can do it. You need to be able to imagine your options and then make concrete decisions.
As a result of strategizing and negotiating, participants created new patterns of behavior to replace those considered ineffective in achieving valued goals. Participants created self-regulatory mechanisms to guide their behaviors. Feedback mechanisms and self-monitoring strategies were integrated within self-regulation processes that guided reward and punishment contingencies for behavioral outcomes. In one participant's words:

When you don't meet your own expectations, you feel upset, you haven't followed through, haven't met your own expectations or lived up to the goals that you've set for yourself. If you set a few rules for yourself, like exercise of some kind every day, then you have a structure to go on, you feel a little more in control. I kept saying I would do something today, I won't eat this today, but until I set myself up some structure, you need some rules.

\section{DISCUSSION}

Our first study in this line of research attempted to catalogue the psychological and social processes involved in the initiation and maintenance of cardiovascular health behavior over time (Fleury, 1991). Empowering potential emerged from a grounded theory methodology as a general explanation for motivation in health behavior change. In the current secondary analysis, we adopted a more detailed approach, also using qualitative methodology. In particular, we examined the role of self-knowledge in motivating health behavior change and the modification of cardiovascular risk. Participants described selfknowledge in terms of three contextually situated patterns: representational, evaluative, and behavioral action. Our results reinforce the motivational role of the self (Sedikides \& Gaertner, 2001; Sedikides \& Gregg, 2006; Sedikides \& Strube, 1997) and highlight the importance of understanding those dimensions of self-knowledge that are relevant to cardiovascular risk reduction. Understanding the dimensions of self-knowledge is necessary for the interpretation, evaluation, and construction of behavioral action plans in cardiovascular risk reduction. A strength of the self-knowledge construct is its multidimensionality, which provides a conceptual foundation for assigning meaning to the process of behavioral change, establishing goals and standards for behavior, gauging one's skills and efficacy, and developing strategies for the regulation of behavioral outcomes (Baumeister \& Vohs, 2004; Pridham, 1993; Stein, 1995; Taylor et al., 1998). 
Across categories of self-knowledge, participants voiced their hopes and fears for future health outcomes and elaborated valued goals, standards, and strategies that guided the initiation and maintenance of behavioral change. These data are consistent with empirically supported conceptualizations of possible selves as self-knowledge structures that contain information about individuals' potential and future (Dunkel \& Kerpelman, 2006; Strauss \& Goldberg, 1999; Waid \& Frazier, 2003). Stated somewhat differently, possible selves represent cognitive manifestations of anticipated goals, motives, fears, and threats that are both individualized and influenced by social and cultural experiences. As such, they can be positive or hoped-for images, or negative, feared selves.

Theorists have conceptualized possible selves as the blueprints for personal growth and change, the foundation for goal-relevant behavior, and as persistent motivators for future behavior (Cross \& Markus, 1991; Ruvolo \& Markus, 1992). The motivational and regulatory functions associated with possible selves have important implications for risk modification in older adults with CHD. The evaluation of possible selves allows insight into personally significant behavioral domains that may provide the basis for risk modification. Understanding these domains is essential, because it is in these domains that individuals will attend to their behavior, generate commitment to behavioral change, and attempt to regulate behavior (Markus, 1983). Older adults have been shown to be significantly more likely to report health-related possible selves than younger adults; regardless of age, those with a hoped-for healthrelated possible self engaged in more healthprotecting behaviors (Fleury et al., 2002; Hooker, 1992; Hooker \& Kaus, 1992, 1994).

Researchers have suggested that, in order to maintain well-being, individuals change and reevaluate their possible selves in response to changing life circumstances (Hooker, 1992; Strauss \& Goldberg, 1999). Such findings are consistent with participants' emphasis on selfknowledge as a mechanism for personal growth. As a basis for continued goal development and achievement, participants engaged in a selfmotivated process of envisioning valued outcomes, evaluating their abilities, and engaging in problem solving and self-regulation. Participants spoke of goals that represented not only valued outcomes, but also valued images of the self or enduring self-definitions (Dunkel \& Kerpelman, 2006). Thus, behavior was motivated to allow participants to grow and change in accordance with a dynamic self-image (Fleury, 1991).
Similarly, in a study examining changes in possible selves over time in older adults, Smith and Freund (2002) found that the dominant motivational orientation in hoped-for selves was improvement or hopes to attain valued goals. The authors concluded that the future-oriented motivational system associated with possible selves functions well into old age. Despite this emphasis on improvement and growth, participants also noted the struggle involved in choosing between alternative values and valued behaviors (CostelloNickitas, 1994; Parse, 1992). This struggle may reflect expectations for goal achievement in light of conflicting values. Participants also evaluated their ability to engage in behavioral change. How the self is represented, particularly with regard to self-conceptions of ability, has been linked to both performance and achievement (Anderman et al., 1999; Cross \& Markus, 1994; Day, Borkowski, Punzo, \& Howsepian, 1994). Perceived efficacy may guide the choice of self-relevant goals and motivation related to specific strategies for goal achievement (Maddux \& Gosselin, 2003). Participants described experiences of both high and low efficacy as dimensions of evaluative selfknowledge in health behavior change. In a study of older adults, Whaley (2003) found that differences in possible selves related to self-efficacy, outcome expectancy, and importance discriminated nonexercisers from exercisers. Similarly, Hooker and Kaus (1994) found that how capable a person felt of avoiding a feared health-related possible self predicted health behaviors in middle-aged adults.

Within the behavioral action process, selfknowledge included relevant plans and selfregulatory strategies for both the achievement of desired outcomes and the avoidance of undesired outcomes. Participants described various selfregulatory mechanisms used in moving from desired goals and self-evaluation to action in risk modification efforts. These aspects of selfknowledge may have motivational potential, as they guide action toward behavioral change and goal achievement (Higgins, 1996; Smith \& Freund, 2002). According to Markus, Cross, and Wurf (1990), when relevant possible selves are combined with self-regulatory strategies for achieving or avoiding these selves, behavioral change is likely to occur. Markus and Wurf (1987) noted that self-knowledge includes procedural knowledge that leads to organized and predictable behavior within a given domain. Indeed, a determinant of success in behavioral change is the process through which the individual manipulates and tests the many possibilities available to direct 
change and, through problem solving, determines the strategies that are congruent with valued goals and perceived ability (Karoly, 1993; Sheldon, 2004). Self-relevant goals and strategies are constructed through repeated experiences within the domain, and once established, include welldefined plans of action (Cantor, 1990; Kihlstrom, Beer, \& Klein, 2003).

Study findings have important implications for the development of interventions designed to promote motivation for risk factor modification in patients with diagnosed CHD. Clinical intervention programs for motivating health behavior change may be designed with an eye toward influencing aspects of the interpretive, evaluative, or behavioral action contexts of self-knowledge. Such interventions would acknowledge the dynamic nature of self-knowledge in addressing an individual's goals, interpretations and expectations, strategies and plans, and use of selfregulatory mechanisms.

Researchers and clinicians may increase their understanding of individual values, goals, perceptions of efficacy, and strategies for health behavior change by using assessments that include an analysis of self-relevant expectations and intentions (Dweck, Higgins, \& Grant-Pillow, 2003; Karoly, 1993; Stein, Roeser, \& Markus, 1998). Through attention to how patients view themselves within the experience of cardiovascular disease, and their unique hopes and fears for the future, intervention efforts may include a refocus of existing goals, development of strategies to anticipate the challenges of behavioral change, and the creation of a self consistent with risk factor modification and recovery (Pridham, 1993). Specific, personalized images of desired goals along with strategies for achieving these goals, may mediate the relationship between positive expectancies, perceived competence, and performance (Whaley, 2003).

The present results build upon and extend traditional motivational theory in that they affirm the central role of the self and self-knowledge in guiding behavioral change. The conceptualization of self-knowledge as a primary component of wellness motivation is an initial step towards understanding the complexities of health behavior change. The present findings provide a basis for the continued examination of the content and function of self-knowledge as an essential link between motivation and health behavior change. The exploration of self-knowledge in wellness motivation allows researchers to move beyond the study of generalized dispositions or taskspecific goals in health behavior change to an examination of the relationships between individual motives and specific actions (Fleury, 1991; Fleury, Sedikides, \& Lunsford, 2001; Fleury et al., 2002).

Additional research is needed to increase our understanding of patient experiences related to behavioral change, including the role of the self in cardiovascular risk modification. Although several cross-sectional studies of the role of the self and health have included older adults (Cross \& Markus, 1991; Hooker, 1992; Ryff, 1991; Waid \& Frazier, 2003), the majority of research has been undertaken with college students and adolescents (Dunkel \& Kerpelman, 2006; Stein et al., 1998). Thus, there are still many questions about the operation of this motivational system among older adults, particularly older adults with chronic illness. Continued exploration of the role of the self in behavioral change is essential to further explain the rehabilitative process, adherence to health behavior change, and positive rehabilitative outcomes. We know little about the dynamic and growth-oriented nature of self-knowledge related to health behavior change, and the responsiveness of aspects of self-knowledge to changing life experiences, such as a diagnosis of CHD (Smith \& Freund, 2002). Further exploration of the content and domains of self-knowledge, particularly those aspects of possible selves linked to the initiation and maintenance of behavioral change are needed as a basis for interventions designed to promote such behaviors. Ongoing research will provide a basis for clinical decision making that acknowledges the central role of the self in risk modification, so that improved treatment and rehabilitation can occur. Such an understanding must include attention to selfknowledge linked to behavioral change processes in patients across social class, cultural, and racial affiliation.

In conclusion, we believe that continued exploration of the role of self-knowledge in guiding health behavior change is essential for increasing adherence to prescribed regimens, for developing interventions that will sustain motivation in behavioral change, and, more generally, for providing a fuller account of the role of motivation in health behavior change.

\section{REFERENCES}

American Heart Association. (2001). Heart and stroke statistical update. Dallas, TX: Author.

Anderman, E.M., Anderman, L.H., \& Griesingner, T. (1999). The relation of present and possible academic 
selves during early adolescence to grade point average and achievement goals. Elementary School Journal, 100, 3-17.

Bagozzi, R.P., Moore, D.J., \& Leone, L. (2004). Selfcontrol and the self-regulation of dieting decisions: The role of prefactual attitudes, subjective norms, and resistance to temptation. Basic and Applied Social Psychology, 26, 199-214.

Baumeister, R.F. (1998). The self. In D.T. Gilbert, S.T. Fiske, \& G. Lindzey (Eds.), Handbook of social psychology (4th ed, pp 680-740). New York: McGraw-Hill.

Baumeister R.F., \& Vohs, K.D. (Eds.), (2004). Handbook of self-regulation: Research, theory, and applications. New York: Guilford Press.

Black, M.E.A., Stein, K.F., \& Loveland-Cherry, C.J. (2001). Older woman and mammography screening behavior: Do possible selves contribute? Health Education and Behavior, 28, 200-216.

Bonanno, G.A., Rennicke, C., \& Dekel, S. (2005). Selfenhancement among high-exposure survivors of the September 11th terrorist attack: Resilience or social maladjustment? Journal of Personality and Social Psychology, 88, 984-998.

Cantor, N. (1990). From thought to behaviour: "Having" and "doing" in the study of personality and cognition. American Psychologist, 45, 735-750.

Cervone, D., Mor, N., Orom, H., Shadel, W.G., \& Scott, W.D. (2004). Self-efficacy beliefs on the architecture of personality: On knowledge, appraisal, and selfregulation. In R.F. Baumeister \& K.D. Vohs (Eds.), Handbook of self-regulation: Research, theory, and applications (pp. 188-210). New York: Guilford Press.

Costello-Nickitas, D.M. (1994). Choosing life goals: A phenomenological study. Nursing Science Quarterly, 7, 87-92.

Cross, S.E., \& Markus, H. (1991). Possible selves across the life span. Human Development, 34, 230-255.

Cross, S.E., \& Markus, H. (1994). Self-schemas, possible selves, and competent performance. Journal of Educational Psychology, 86, 423-438.

Curtis, S., Gesler, W., Smith, G., \& Washburn, S. (2000). Approaches to sampling and case selection in qualitative research: Examples in the geography of health. Social Science \& Medicine, 50, 10011014.

Day, J.D., Borkowski, J.G., Punzo, D., \& Howsepian, B. (1994). Enhancing possible selves in Mexican American students. Motivation and Emotion, 18, 79-103.

Dunkel, C. (2000). Possible selves as a mechanism for identity exploration. Journal of Adolescence, 23, 519-529.

Dunkel C.S. \& Kerpelman J. (Eds.), (2006). Possible selves: Theory, research and applications. Huntington, NY: Nova Science.

Dweck, C.S., Higgins, E.T., \& Grant-Pillow, H. (2003). Self-systems give unique meaning to self variables. In M.R. Leary \& J.P. Tangney (Eds.), Handbook of self and identity (pp. 239-252). New York: Guilford Press.

Fleury, J. (1991). Empowering potential: A theory of wellness motivation. Nursing Research 40, 286-291.

Fleury, J. (1996). Wellness motivation theory: An exploration of theoretical relevance. Nursing Research, 45, 277-283.

Fleury, J., Sedikides, C., \& Donovan, K. (2002). Possible health selves of older African Americans: Toward increasing the effectiveness of health promotion efforts. Topics in Geriatric Rehabilitation, 18, $52-58$.

Fleury, J., Sedikides, C., \& Lunsford, V. (2001). Women's experience following a cardiac event: The role of the self in healing. Journal of Cardiovascular Nursing, 15, 71-82.

Gollwitzer, P.M., Fujita, K., \& Oettingen, G. (2004). Planning and the implementation of goals. In R.F. Baumeister \& K.D. Vohs (Eds.), Handbook of self-regulation: Research, theory and applications (pp. 211-228). New York: Guilford Press.

Guba, E.G., \& Lincoln, Y.S. (2005). Paradigmatic controversias, contradictions, and emerging confluences. In N. Denzin \& Y. Lincoln (Eds.), The SAGE handbook of qualitative research (pp. 191215). Thousand Oaks, CA: Sage.

Heidrich, S.M., \& Ryff, C.D. (1993). Physical and mental health in later life: The self-system as mediator. Psychology and Aging, 8, 327-338.

Higgins, E.T. (1996). The "self digest": Selfknowledge serving self-regulatory functions. Journal of Personality and Social Psychology, 71, 10261083.

Hooker, K. (1992). Possible selves and perceived health in older adults and college students. Journal of Gerontology: Psychological Sciences, 47, 85-95.

Hooker, K., \& Kaus, C.R. (1992). Possible selves and health behaviors in later life. Journal of Aging and Health, 4, 390-411.

Hooker, K., \& Kaus, C.R. (1994). Health-related possible selves in young and middle adulthood. Psychology and Aging, 9, 126-133.

Hsieh, H.F., \& Shannon, S.E. (2005). Three approaches to qualitative content analysis. Qualitative Health Research, 15, 1277-1288.

Karoly, P. (1993). Goal systems: An organizing framework for clinical assessment and treatment planning. Psychological Assessment, 5, 272-280.

Kendzierski, D. (1997). Exercise self-schemata: Cognitive and behavioral correlates. Health Psychology, 9, 69-82.

Kihlstrom, J.F., Beer, J.S., \& Klein, S.B. (2003). Self and identity as memory. In M.R. Leary \& J. Tangney (Eds.), Handbook of self and identity (pp. 68-90). New York: Guilford Press.

Krummel, D.A., Koffman, D.M., Bronner, Y., Davis, J., Greenlund, K., Tessaro, I., et al. (2001). Cardiovascular health interventions in women: What works? Journal of Women's Health \& Gender-Based Medicine, 19, 117-136. 
Leondari, A., Syngollitou, E., \& Kiosseoglou, G. (1998). Academic achievement, motivation, and future selves. Educational Studies, 4, 153-163.

Lincoln, Y., \& Guba, E. (1985). Naturalistic inquiry. Beverly Hills, CA. Sage.

Maddux, J.E., \& Gosselin, J.T. (2003). Self-efficacy. In M.R. Leary \& J.P. Tangney (Eds.), Handbook of self and identity (pp. 218-238). New York: Guilford Press.

Markus, H. (1983). Self-knowledge: An expanded view. Journal of Personality, 51, 543-565.

Markus, H., Cross, S., \&Wurf, E. (1990). The role of the self-system in competence. In R.J. Sternberg \& J. Kolligian, Jr. (Eds.), Competence considered (pp. 205-225). New Heaven, CT: Yale University Press.

Markus, H., \& Nurius, H. (1986). Possible selves. American Psychologist, 41, 954-969.

Markus, H., \& Wurf, E. (1987). The dynamic selfconcept: A social psychological perspective. Annual Review of Psychology, 38, 299-337.

Miller, N.H., Hill, M., Kottke, T., \& Ockene, I.S. (1997). The multilevel compliance challenge: Recommendations for a call to action. A statement for healthcare professionals. Circulation, 97, 1085-1090.

Mischel, W., \& Morf, C.C. (2003). The self as a psychosocial dynamic processing system: A metaperspective on a century of the self in psychology. In M.R. Leary \& J.P. Tangney (Eds.), Handbook of self and identity (pp. 15-46). New York: Guilford Press.

Oettingen, G., \& Gollwitzer, P.M. (2001). Goal setting and goal striving. In A. Tesser \& N. Schwarz (Eds.), The Blackwell handbook of social psychology (pp. 329-347). Oxford, UK: Blackwell.

Oyserman, D., Bybee, D., Terry, K., \& Hart-Johnson, T. (2004). Possible selves as roadmaps. Journal of Research in Personality, 38, 130-149.

Oyserman, D., \& Fryberg, S. (2006). The possible selves of diverse adolescents: Content and function across gender, race and national origin. In C. Dunkel \& J. Kerpelman (Eds.), Possible selves: Theory, research, and application (pp. 17-39). Huntington, NY. Nova.

Oyserman, D., Gant, L., \& Ager, J. (1995). A socially contextualized model of African-American identity: Possible selves and school persistence. Journal of Personality and Social Psychology, 69, 1216-1232.

Oyserman, D., Terry, K., \& Bybee, D. (2002). A possible selves intervention to enhance school involvement. Journal of Adolescence, 25, 313-326.

Patton, M.Q. (2002). Qualitative research and evaluation methods (3rd ed.). Newbury Park, CA: Sage.

Parse, R.R. (1992). Human becoming: Parse's theory of nursing. Nursing Science Quarterly, 5, 35-42.

Pridham, K.F. (1993). Anticipatory guidance of parents of new infants: Potential contribution of the internal working model construct. Image, 25, 49-56.

Quellette, J.A., Hessling, R., Gibbons, F.X., ReisBergan, M., \& Gerrard, M. (2005). Using images to increase exercise behavior: Prototypes versus possible selves. Personality and Social Psychology Bulletin, 31, 610-620.

Roberts, B.W., O’Donnell, M., \& Robins, R.W. (2004). Goal and personality trait development in emerging adulthood. Journal of Personality and Social Psychology, 87, 541-550.

Ruvolo, A.P., \& Markus, H.R. (1992). Possible selves and performance: The power of self-relevant imagery. Social Cognition, 10, 95-124.

Ryff, C.D. (1991). Possible selves in adulthood and old age: A tale of shifting horizons. Psychology and Aging, 6, 286-295.

Sandelowski, M. (1995). Sample size in qualitative research. Research in Nursing \& Health, 18, 179183.

Sandelowski, M. (2000). Whatever happened to qualitative description? Research in Nursing \& Health, 23, 334-340.

Sedikides, C. (2003). On the status of self in social prediction: Comment on Karniol. Psychological Review, 110, 591-594.

Sedikides, C., \& Gaertner, L. (2001). A homecoming to the individual self: Emotional and motivational primacy. In C. Sedikides \& M.F. Brewer (Eds.), Individual self, relational self, collective self (pp. 723). Philadelphia. Psychology Press.

Sedikides, C., Gaertner, L., \& Toguchi, Y. (2003). Pancultural self-enhancement. Journal of Personality and Social Psychology, 84, 60-70.

Sedikides, C., \& Green, J.D. (2000). On the selfprotective nature of inconsistency/negativity management: Using the person memory paradigm to examine self-referent memory. Journal of Personality and Social Psychology, 79, 906-922.

Sedikides, C., \& Green, J.D. (2004). What I don't recall can't hurt me: Information negativity versus information inconsistency as determinants of memorial self-defense. Social Cognition, 22, 4-29.

Sedikides, C., \& Gregg, A.P. (2003). Portraits of the self. In M.A. Hogg \& J. Cooper (Eds.), Sage handbook of social psychology (pp. 110-138). London: Sage.

Sedikides, C., \& Gregg, A.P. (2006). The self as a point of contact between social psychology and motivation. In P.A.M. van Lange (Ed.), Bridging social psychology: Benefits of transdisciplinary approaches (pp. 233-238). Mahwah, NJ: Erlbaum.

Sedikides, C., \& Strube, M.J. (1997). Self-evaluation: To thine own self be good, to thine own self be sure, to thine own self be true, and to thine own self be better. In M.P. Zanna (Ed.), Advances in experimental social psychology (Vol. 29, pp. 209-269). New York: Academic Press.

Sheldon, K.M. (2004). Optimal human being: An integrated multi-level perspective. Mahwah, NJ. Erlbaum.

Shepard, B. (2003). Creating selves in a rural community [On-line]. In W.M. Roth (Ed.), Connections' 03 (pp. 111-120). Retrieved September 20, 2005 from: http://www.educ.uvic.ca/Research/ conferences/connections2003/07Shepard102.pdf 
Smith, S.C., Blair, S.N., Bonow, R.O., Brass, L.M., Cerqueira, M.D., Dracup, K., et al. (2001). AHA/ ACC Scientific Statement: AHA/ACC guidelines for preventing heart attack and death in patients with atherosclerotic cardiovascular disease: 2001 update: A statement for healthcare professionals from the American heart Association and the American College of Cardiology. Journal of the American College of Cardiology, 38, 1581-1583.

Smith, J., \& Freund, A.M. (2002). The dynamics of possible selves in old age. Journal of Gerontology, 57B, 492-500.

Stein, K.F. (1995). Schema model of the self-concept. Nursing Research, 27, 187-193.

Stein, K.F., Roeser, R., \& Markus, H.R. (1998). Selfschemas and possible selves as predictors and outcomes of risky behaviors in adolescents. Nursing Research, 47, 96-106.

Strauss, R., \& Goldberg, W.A. (1999). Self and possible selves during the transition to fatherhood. Journal of Family Psychology, 13, 244-259.
Taylor, S.E., Pham, L.B., Rivkin, I.D., Armor, D., \& Adams, J.L. (1998). Harnessing the imagination: Mental simulation, self-regulation, and coping. American Psychologist, 53, 429-439.

Unemori, P., Omoregie, H., \& Markus, H.R. (2004). Self-portraits: Possible selves in European-American, Chilean, Japanese and Japanese-American cultural contexts. Self and Identity, 3, 321-328.

Waid, L.D., \& Frazier, L.D. (2003). Cultural differences in possible selves during later life. Journal of Aging Studies, 17, 251-268.

Whaley, D.E. (2003). Future-oriented self-perceptions and exercise behavior in middle aged women. Journal of Aging and Physical Activity, 11, 1-17.

Yowell, C.M. (2000). Possible selves and future orientation: Exploring hopes and fears of Latino boys and girls. Journal of Early Adolescence, 20, 245-280.

Yowell, C.M. (2002). Dreams of the future: The pursuit of education and career possible selves among ninth grade Latino youth. Applied Developmental Science, 6, $62-72$. 